\title{
The task of the modern educator is not to cut down jungles, But to irrigate deserts.
}

\author{
${ }^{1}$ Mrs. Moushumi Banerjee, ${ }^{2}$ Miss Priya Shiva, \\ ${ }^{1}$ Dept. Of Hotel Management, Mjpru, India \\ ${ }^{2}$ Dept. Of Hotel Management, Mjpru, India
}

\begin{abstract}
The role of an effective management teacher is quality teaching. Quality teaching in higher education matters for student learning outcomes. But fostering quality teaching presents higher education institutions with a range of challenges at a time when the higher education sector is coming under pressure from many different directions. Institutions need to ensure that the education they offer meets the expectations of students and the requirements of employers, both today and for the future. Yet higher education institutions are complex organizations where the institution-wide vision and strategy needs to be well-aligned with bottom-up practices and innovations in teaching and learning. Developing institutions as effective learning communities where excellent pedagogical practices are developed and shared also requires leadership, collaboration and ways to address tensions between innovators and those reluctant to change.

Efficient management teacher uses pedagogical techniques to produce learning outcomes for students. It involves several dimensions, including the effective design of curriculum and course content, a variety of learning contexts (including guided independent study, project-based learning, collaborative learning, experimentation, etc.), soliciting and using feedback, and effective assessment of learning outcomes. His role also involves to provide well-adapted learning environments and student support services.
\end{abstract}

A key insight from complex systems is that simple solutions are not likely to be effective in cases such as the education system, and that providing a balance or coexistence of what seem to be opposites may provide the greatest opportunities for successful courses of action. In the following we consider:

- Integrating the commonly polarized goals of education; i.e. the goal that focuses on transmitting knowledge with the goal that emphasizes the development of the individual student.

- Adapting teaching to different student characteristics by using diverse methods of teaching. Adaptation to the ability levels, patterns of different abilities, learning styles, personality characteristics, and cultural backgrounds.

- Integrating the curriculum by developing inter-disciplinary curriculum units that enable students to acquire knowledge from different disciplines through a unifying theme while having the opportunity to contribute in different and special ways to the objectives of the integrated units.

Among the most difficult problems faced by the education system are those associated with teaching effectiveness. The current preparation of teachers for specific age levels, specific subject matter, specific academic skills, etc., does not take into consideration sufficiently the complexity of factors such as students various characteristics. There is a strong need to train teachers to adapt instruction to the diverse student abilities, learning styles, personality traits and needs by using more differentiated teaching strategies.

It thus causes a big gap between what the industries need and what is being offered by the management institutes in terms of the academic input, skills set and work experience to management students. It is this wide gap which causes mismatching of demand and supply ratio of the management trainees.

Keywords: curriculum ,effective assessment, pedagogical practices, quality teaching, management teacher

\section{Introduction}

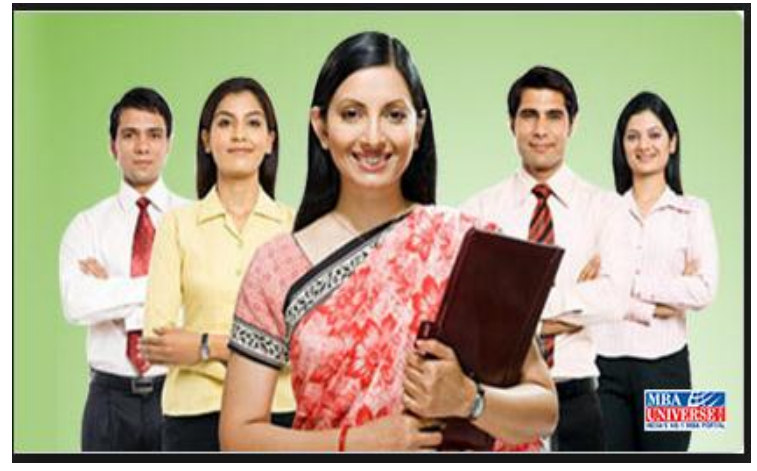


Management institutes and industry, which for long have been working in separate domains, are rapidly coming closer to each other to create synergies. The constantly changing management parameters, in response to growing complexity of the business environment today have necessitated these two to come closer. Higher education institutions not only contribute skilled human resources to business, but also in various intangible ways. The intersecting needs and mutually interdependent relationship requires identifying means of further strengthening management university-industry partnerships.

Dynamic business world and the rapidly developing knowledge based service economy have put an increased demand for professionals to manage the business effectively. This is precisely the reason why amongst various other fields of knowledge, desire for acquiring management qualifications is growing, both amongst the fresh graduates and working executives.

\subsection{History Of Management Education In India}

\begin{tabular}{|c|c|c|c|}
\hline \multicolumn{4}{|c|}{ 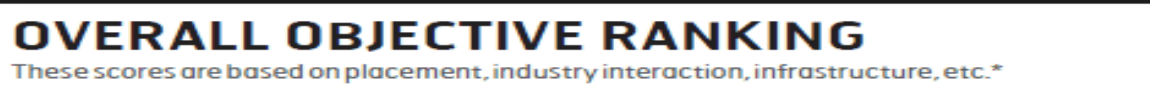 } \\
\hline $\begin{array}{l}\text { Ranke } \\
(2013)\end{array}$ & $\begin{array}{l}\text { Ranle } \\
\text { (2012) }\end{array}$ & Name of the B-School & $\begin{array}{c}\text { Grand Total } \\
(930)\end{array}$ \\
\hline 1 & 1 & Indian Institute of Management, Ahmedabad & 813 \\
\hline 2 & 3 & XLRI, Jamshedpur & 770 \\
\hline 3 & 5 & Faculty of Management Studies, Delhi & 767 \\
\hline 4 & 4 & SP Jain Institute of Management $\varepsilon$ Research, Mumbai & 752 \\
\hline 5 & 6 & National Institute of Industrial Engg. Mumbai & 733 \\
\hline 6 & 8 & Indian Institute of Management, Kozhikode & 721 \\
\hline 7 & 7 & SVKM's NMIMS School of Business Mgmt, Mumbai & 707 \\
\hline $\mathbf{8}$ & 12 & Indian Institute of Management, Indore & 706 \\
\hline $\mathbf{9}$ & 9 & Institute of Management Technology. Ghaziabad & 703 \\
\hline 10 & 13 & Shailesh J Mehta School of Management, IIT Mumbai & 697 \\
\hline
\end{tabular}

In India, before the 60 's, business education was not offered as a separate area of specialization. Employees in the businesses were mostly graduates or postgraduates in 'COMMERCE' stream. In the 1960's, business education formally starting gaining importance in India with the establishment of two Indian Institute of Management; IIM CALCUTTA in association with Sloan School of Management and IIM AHAMDABAD with Harvard Business School. After that there has been a relatively slow but steady growth in number of institutes and popularity of business education in India. A massive growth in the number of business schools was observed post 1991 when India was liberalized and opened to the global world. Many multi-nationals entered India bringing with them increased demand for professionals. Business education now moved beyond the domains of government control with establishment of many private institutions.

\subsection{Need For Management Professionals In India}

India sees wealth creation as a great equalizer amongst all sections of the society. In such a scenario a KNOWLEDGE WORKER who can work at the cutting edge of technology, add value to the bottom-line, and provide competitive advantage to industry has become a hot commodity to acquire. With such huge demand for business education, in year 2004, the number of business schools in India has grown to 1320 from just 130 in the year 1991, offering more than 75,000 seats. More than $80 \%$ increase in number of business schools is coupled with increase in number of students competing for admission to the above. Each year more than 1.5 Lakh students in India compete for admission to prestigious business schools.

\subsection{Objectives}

The primary research has been taken up with following objectives:

- To identify the areas where management institutions include industry participation;

- To assess the perceived benefit acquired from this partnership in specific areas ;

\subsection{Research Methodology}

Secondary data has been collected from Deans and Directors of Business Schools in India. The data was collected from brochures and sites of B-Schools. They were asked for information through students and teachers to rate the extent of their business schools collaborating with industry on 23 listed areas on a scale of 1 to 5. (1 being the lowest level of collaboration/ or the benefit accrued and 5 being the highest degree of collaboration/ or benefit accrued). The mean of the responses were taken to get degree of collaboration and the perceived benefit in specific areas. 


\section{Need For University-Industry Interface}

According to Friga, Bettis and Sullivan (2003) the trends of evolution of management education indicate that knowledge creation is becoming more students based. This will usher in a variety of changes including paradoxically a trend towards close interaction among students, industry and the faculty.

Academia- Industry Interface could be defined as interactive and collaborative arrangement between academic institutions and business corporations for the achievement of certain mutual goals and objectives. Traditionally, business schools were looking for placements and internships for their students and the industry for fresh recruits who are well trained and equipped with the right KSA(knowledge, skills and attitude) to be able to contribute to organization's growth.

Bisoux (2003) has explored the relationship between academics and industry. He says that corporations are placing growing emphasis on finding the "right person". It forces the management institutes to think more carefully on whom they hire, and therefore the role of industry in the entire management institute model becomes important.

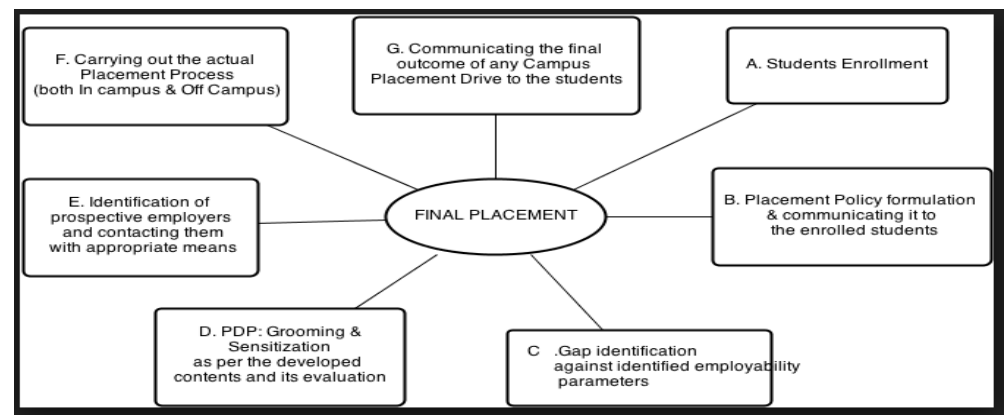

The Management institutes have realized the importance of 'working closely with employers' for the following reasons:

* Increasing complexity in academic and business world and constantly changing needs of the industry;

* Increasing criticality of human competence in creating and sustaining competitiveness of the organizations;

* Shift in management parameters of management institutes from earlier academic models to revenue based models. ;

* Growing competition for student placements and industry mind-share, with rapid increase in the number of management institutes and hence the management graduates;

* Growing pressure from industry to make their fresh inductees productive from day one to reduce the subsequent training costs. Greenberger (2001) is of the view that organizations today are looking for trained professionals and students capable of taking decisions. Some of the training in formative years comes out from business corporations, via collaborative internships with corporations to enhance learning opportunities to students;

* Increasing interdependence between academia and industry to satisfy need for sustenance and innovation in their respective areas.

1. Guest Lectures by industry representatives.

\section{How They Synergise?}

2. Suggestions in curriculum and content designing.

3. Executive Education and Management Development Programmes.

4. Joint seminars by academia and industry both for executives and students.

5. Consulting on management and related issues by academia;

6. Academia generating ideas and acting as incubators to new business.

7. Inclusion of industry experts in governing councils and other board of studies.

8. Industry providing financial and infrastructure support to management institutes for their development.

9. Funding academic and applied research.

According to an article published in Economic Times (November 2004),

- Management Development Institute (MDI) as a matter of policy has $20 \%$ faculty from corporate who has served in top management positions for more than 15-20 years. 
- IILM has formed joint advisory groups with corporate for collaborative consulting and organizing management development programmes. Students are assigned Industry mentors for two years, with an objective to groom them for the future challenges.

\section{Drawbacks Of Management Programmes}

1. According to Elliot et al. (1994) MBA programmes place too much emphasis on quantitative and analytical skills and neglect human skills and do little to produce managers who are capable of meeting challenges of global business environment and cope with increasingly diverse workforce.

2. Byrne (1991) says that companies demand more relevance today. He adds that MBA programmes provide less relevance with the job, are felt to be too long and insufficiently flexible. To improve the quality of output, more and more business corporations are looking to collaborate in more detail with business schools to create programmes, which can be customized according to company's individual needs and requirements.

3. Academics have been including the industry inputs into their curriculum and course designing without assessing the effectiveness of such corporate representatives to these committees. Today it is just a matter of pride for these schools to adorn their councils with big names from industry, with an objective to score high on INDUSTRY INTERFACE parameter in the ratings and rankings being done by every other business magazine in India. Executives from corporate are invited to take up an entire course or few lectures with prime objective of getting them on campus for placements, but the learning, students acquire from these lectures is not evaluated.

4. There is not enough evidence available in India of the benefits to business corporations from the research done in management institutes. Since most of this research is exploratory rather than innovative, the utility of the same to the industry is rather low.

In the present day world, the entire concept of "working with employers" is a relatively narrow understanding of this association. Multi-level collaboration is needed so that the two entities can contribute to each other's growth. It is important to identify these areas where optimum collaboration is possible rather than giving business corporations a carte blanc' in this matter.

\section{Figures and Tables}

TABLE: 1Extent of collaboration with the industry

The top five modes by which business schools collaborate with industry are:

\begin{tabular}{|l|l|l|l|}
\hline $\begin{array}{l}\text { S } \\
\text { N } \\
\text { o } \\
\cdot\end{array}$ & Areas of collaboration & $\begin{array}{l}\text { Mean } \\
\text { score }\end{array}$ & $\begin{array}{l}\text { Standar } \\
\text { d } \\
\text { Deviation }\end{array}$ \\
\hline 1 & Guest Lectures & $\begin{array}{l}3 . \\
9\end{array}$ & 0.63 \\
\hline 2 & Training and Internship of students & $\begin{array}{l}3 . \\
7\end{array}$ & 1.10 \\
\hline 3 & Including industry into Governing Councils and & $\begin{array}{l}3 . \\
5\end{array}$ & 1.30 \\
\hline 4 & Board of studies & $\begin{array}{l}3 . \\
3\end{array}$ & 1.70 \\
\hline 5 & Executive Education programmes & $\begin{array}{l}3 . \\
2\end{array}$ & 1.40 \\
\hline
\end{tabular}

TABLE: 2 The least preferred modes of collaboration are:

\begin{tabular}{|l|l|l|l|}
\hline $\begin{array}{l}\text { S. } \\
\text { No. }\end{array}$ & Areas of collaboration & $\begin{array}{l}\text { Mean } \\
\text { score }\end{array}$ & $\begin{array}{l}\text { Standard } \\
\text { Deviation }\end{array}$ \\
\hline 1 & Faculty selection & 1.5 & 1.08 \\
\hline 2 & Joint community development services & 1.7 & 1.30 \\
\hline 3 & Helping industry in training and selection of their staff & 2.0 & 1.51 \\
\hline 4 & Financial support from industry for academic activities & 2.2 & 1.55 \\
\hline 5 & Providing incubator services for start up companies/ ideas & 2.2 & 1.40 \\
\hline
\end{tabular}

\section{Analysis}

\&o According to the data, guest lectures are the most popular mode of industry interface. Guest lectures are sessions taken up by executives in addition to classes taken up by professional teachers. The objective of 
this is to give students an overview of industry practices and help them relate the theory to real life applications.

At IILM, it is mandatory for the instructor to arrange minimum of six industry sessions in the thirty-two session course. Indian School of Business and Media (ISB\&M) organizes more than 300 guest lectures for MBA students every year.

\&o The second most preferred mode is establishing partnership through training and internships of students. This method is a self-feeding method. Industry gets a first hand feel of students in a business school, thus increasing their placement opportunities and strengthening long term relationship between the two entities. Involving industry in student training and internships has become mandatory in business curriculum in Indian business schools.

\footnotetext{
All students have to spend two months with corporate working on a specific project to gain hands on experience.

\&o The inclusion of executives in the Governing Councils and Board of Studies in business schools is third preferred mode of collaboration. The objective of having industry representation is to include the latter's view in governance and other activities of management universities
}

Adorning these councils with the known names in industry is perceived to enhance the image and recall value of the institution, which not only attracts prospective students, donors and other stakeholders but also work in favour of business schools during ratings and rankings.

80 Executive Education is a long-term management training programmes for working executives transpires to be the fourth most preferred mode of university-industry partnership.Rao and Bowonder (2004), conducted a study on Management Education in India, which shows that there is a fundamental shift in management university offerings away from traditional MBA programmes to more part-time and executive education programmes.

Indian Institute of Management (IIMs) has been giving their domains to executive education on modular classes to facilitate executives' involvement and strike relationship with organizations.

XLRI (India) among others have created a Partnership Model with organizations for Executive Education initiatives. Management Development Institute (MDI), one of the top business schools in India was established with the prime objective of imparting management education to executives and government officials.

Today, even after expanding itself into other forays, it still conducts six month to one year National Management programmes (NMP) for company sponsored executives and civil services officials. These initiatives besides increasing the industry mind-share also fetch revenue to business schools.

\&o Finally, the management faculty is slowly integrating the industry's views into their curriculum.Miller (1993) identifies significant revisions in curriculum and contents, which are undertaken in management university, with an objective of including industry recommendations. Many management university in India have been inviting suggestions from industry to update their curriculum and include the topics of present day relevance. This is done with a view of imparting the knowledge and skills set, needed by graduating students in constantly changing global business environment.

Table 2 gives a brief summary of the least preferred modes of collaboration. It is clearly evident that business schools do not wish to synergise with industry on their internal issues. Faculty \& staff selection, training and development are viewed as in-house activities, where industry's participation is not invited.

In view of government's increased interest in education and the latter being included as crucial issues in WTO debate, there has been increased spending on development of higher education in India. The cash rich private institutions are today less dependent on industry for funding and infrastructure support. They not only have donors but also generate income from consulting, executive education initiatives to support their functions.

University-Industry interface has not been considered through providing of incubator services to industry for new start-ups by commercializing the ideas given by academic fraternity and helping corporate grow in initial years. Industry has shown limited interest in including academia into their strategic decisions regarding new business ideas, decreasing the chances of partnerships in this area.

\section{Conclusion \& Recommendations}

- It is imperative for management university to bring university and Industry closer and build strong collaborative relationship; 
- Each management university needs to identify the areas where they can build an effective universityindustry relationship. They need to revisit their mission and academic model to be able to identify the right Interface mix;

- It is not a must that all modes of partnership are equally beneficial to every business school. They have to work on 'differential relationship' mechanism.

- University and Industry need to take build organic relationships, with long term strategic intent contributing to growth and development of both the entities;

- The research supports that Indian management university have been traditionally using guest lectures as the most preferred medium of industry collaboration. They are not only considered as a medium to establish industry networks, by giving latter an experience of institute and the students and increasing placement opportunities but also add to the learning value for students.

- Management university essentially have collaborated with corporate to provide training and internships to students. Two-month internships are integral part of business curricula in India with certain credit assigned. This is seen as one of the best methods of giving students both the theoretical concepts and their applications and enhancing their ability to relate the two for decision making purpose;

- Executive Education and Management Development Programmes are two important areas where Indian business schools are foraying. These initiatives on the part of business schools trigger industry's interest to collaborate by assisting them in development and training of their human capital, hence increasing the mind-share and enhancing the image of the business school. This kind of partnership model is still in initial stages in India, with a need to work on appropriate strategy for mutual benefit.

- Including industry inputs has been perceived quite beneficial by business schools (3.9) in improving the quality of output and making them competent of surviving in rapidly changing business environment. However, not many institutions have been able to work on the right method of including the industry's viewpoints into curriculum and structuring the course for student and corporate benefit.

\section{References}

[1]. Adrian S. \& Matheson R.A, (1996) "Management Training- are business schools out of touch with their market?", Journal of European Industrial Training, MCB University Press.

[2]. Altbach Philip G., "Higher education and WTO: Globalization Among", International Higher Education no.3, The Boston College Center for International Higher Education.

[3]. Aggarwal A., Rizvi I.A \& Popli S. (2004), "Global Branding of Business Schools: An Indian Perspective”, Welingkars Research Journal, Volume II, Issue-4, pp 2-31.

[4]. Beard C., (1994) "Educating the star fleet captin-making business schools more relevant to their stakeholders:, Working paper, University of Paisley, June 1994

[5]. Bhada Yezdi K. (2002), "Top of the Class”, Bized November/ December 2002 AASCB Publication pp.22-27

[6]. Bisoux Tricia (2003), "New Directions in Global Education”, Bized January/ February 2003 AACSB Publication, pp34-37

[7]. Bisoux Tricia (2003), "B-Schools with Global Perspective", Bized September/ October 2003, AACSB Publication pp 28-39

[8]. Byrne J.A, (1991) "Back to School”, Business Week, October 1991, pp 94-9-39.

[9]. Byrne J.A (1993), "Business Week's guide to the Best Executive Education programmes", McGraw Hill, New York.

[10]. Conway Tony, Mackay Stephen \& Yorke David (1994), "Strategic Planning in Higher Education: Who are the customers", International Journal of Educational Management Vol.8, No.6, MCB University press, pp. 29-36

[11]. Elliot, C.J., Goodwin J.S \& Goodwin J.C., (1194) "MBA programmes and business needs: is there a mismatch?", Business Horizins, July-August 1994, pp 55-60.

[12]. Gleason Jan (2001), "Living your Brand", Communications and Advocacy for Colleges, Universities, Research and Related Organizations, Counselors to Higher Education and Public relations Society of America Vow 1 issue IV

[13]. Gray Brendan J., Fam Kim Shyam \& Llanes Violeta A. (2003), "Branding universities in Asian markets", Journal of product \& Brand Management MCB Up Limited, Vol 12 no. 2, pp. 108-120

[14]. Miller C. ( July 1993), "MBA programs revised to meet leaner demands of business", Marketing News, American Marketing Association, pp 1-19.

[15]. Popli S. (2002) "Customer Satisfaction: Quality Approach to Management Education", paper presented at $7^{\text {th }}$ International conference on Quality in Higher Edducation at RMIT, Australia. 